\title{
TISSUE DISTRIBUTION OF PENICILLINS
}

\author{
D. M. BROWN \\ Beecham Research Laboratories, Brentford, Middlesex.
}

WHILE it is of obvious importance to determine the antibacterial activity of a penicillin in the blood it is perhaps of greater importance to know what concentrations are present in the extravascular fluids. In view of the current interest in protein binding and its influence on activity it is also of importance to determine in what way binding influences distribution throughout the body.

Usually methods for estimating tissue levels of antibiotics have consisted mainly of grinding the tissue or organ in a homogeniser with the appropriate buffer, spinning down the debris and estimating the penicillins in the supernatant. The total amount of penicillin present is calculated and then expressed as the amount per gram of tissue, wet or dry weight. However these figures give very little information about the actual tissue levels. Depending on the vascularity of the organs they may reflect largely the blood levels. Alternatively, they may give quite erroneous results due to specific concentration within the organ, for example, the high levels found in the liver and kidney merely reflect the high concentration in the bile and urine. It is highly improbable that there is specifically high concentration of the antibiotics in the intracellular space of the liver and kidney. Hence it is very difficult to get a true figure for the amount of penicillin in tissues. We therefore estimated the concentration of penicillin in inflammatory fluids and lymph which can be obtained in adequate quantities for assay purposes. In addition we determined the penicillin concentration in granuloma tissue. For the studies, four penicillins were selected-phenethicillin, phenoxymethylpenicillin, cloxacillin and ampicillin.

In order that all the results should pertain to the one species the serum protein binding was determined for each using rat serum by the ultrafiltration technique. The assay procedure was the cup plate technique using Sarcina lutea as the test organism, the usual precautions necessary for assaying in the presence of protein being observed. (Table I).

TABLE I.

Binding of the Listed Penicillins to Rat Serum

\begin{tabular}{lc}
\hline Penicillin & \% Bound \\
Ampicillin & 5.2 \\
Cloxacillin & 81.5 \\
Phenoxymethylpenicillin & 77.4 \\
Phenethicillin & 84.3 \\
\hline
\end{tabular}

Since it is generally agreed that penicillin combines reversibly only with the albumin fraction of tissue protein, it was also of interest to see if differences in the albumin content of the body fluids could influence the penetration from serum. We therefore estimated the total amount of protein by the micro-biuret method in the autoanalyser and the albumin/globulin ratios were determined by electrophoresis. The results are given in Table II.

TABLE II

\begin{tabular}{lcc}
\hline \multicolumn{1}{c}{ Sample } & $\begin{array}{c}\text { Total Protein } \\
\text { gms. } \%\end{array}$ & $\begin{array}{c}\text { Albumin/ } \\
\text { Globulin Ratio }\end{array}$ \\
Rat Lymph. & 3.2 & $1.33: 1$ \\
Rat Peritoneal & Fluid. & 1.8 \\
Rat Serum. & 6.8 & $1.2: 1$ \\
\hline
\end{tabular}



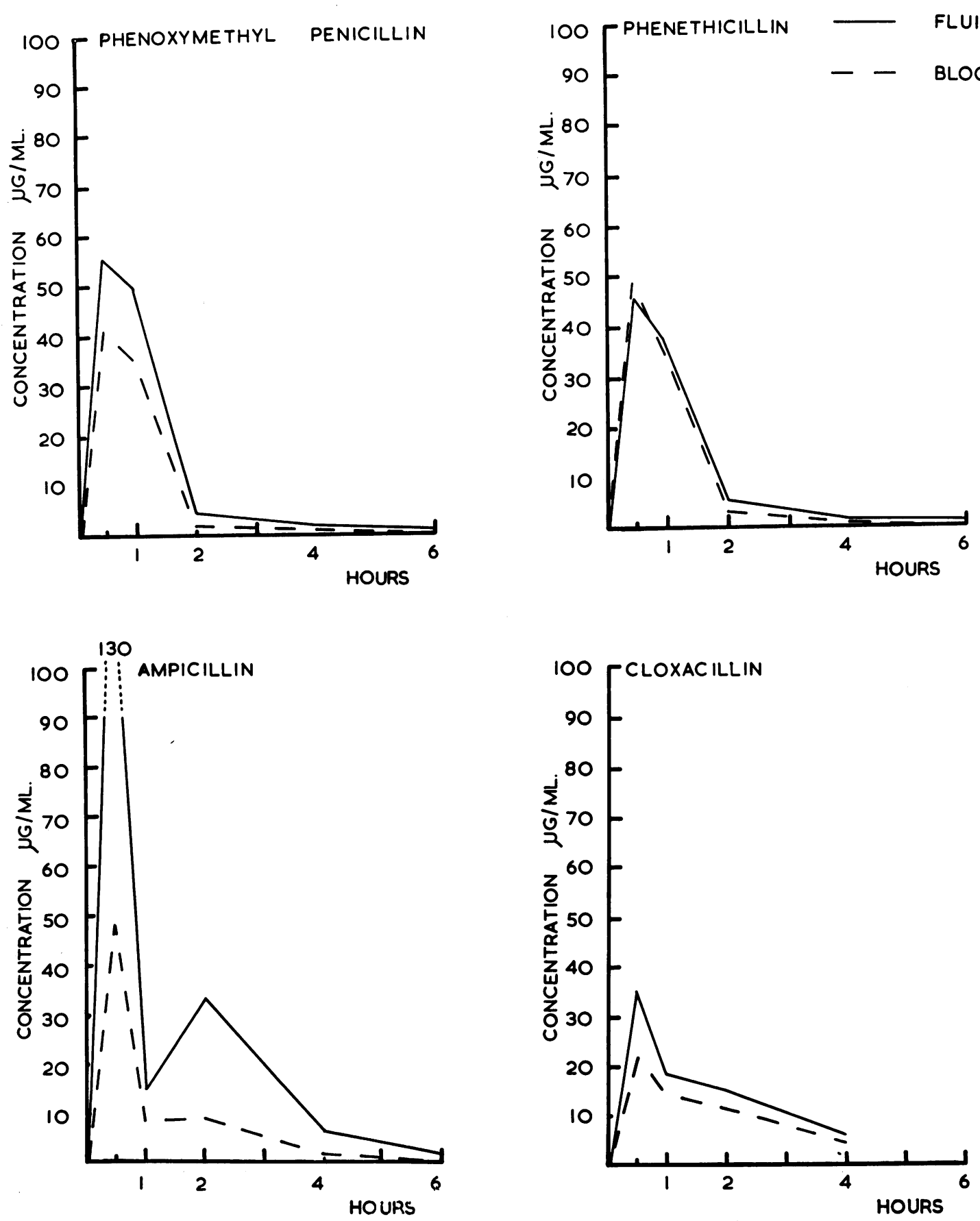

FIG. 1.-Concentrations of Penicillins $\mu \mathrm{g} . / \mathrm{ml}$. in Blood and Inflammatory Peritoneal Fluid of Rats following the Intramuscular Administration of $100 \mathrm{mg} . / \mathrm{kg}$. of the Penicillins. 
To estimate the concentration of penicillin in inflammatory fluids groups of ten rats of average weight 150 gms., ten per group, were injected intraperitoneally with $0.1 \mathrm{ml}$. turpentine. Immediately afterwards the penicillin being investigated was injected intramuscularly into the left hind limb at a dose of $100 \mathrm{mg} . / \mathrm{kg}$. At $\frac{1}{2}, 1,2,4$ and 6 hours afterwards the rats were killed and the peritoneal fluid withdrawn, a blood sample was also removed, and assayed. The fluid was diluted with $\mathbf{M} / 20$ phosphate buffer $\mathrm{pH} 7.2$ for assay. The results are shown in Figure 1.

The serum and inflammatory fluid concentrations are similar with phenethicillin whereas the inflammatory fluid concentrations are slightly higher than the blood levels with phenoxymethylpenicillin and cloxacillin. However ampicillin gives much higher levels in the inflammatory fluid than the blood. Irrespective of the degree of protein binding one would expect equal concentrations of antibiotics on either side of the capillary wall provided one assumes that the capillaries function as semi-permeable membranes and the concentrations of protein in the serum and intraperitoneal fluids are the same. Since the total concentration of ampicillin is much greater in the inflammatory fluid than the serum, simple equilibrium conditions do not appear to exist, and the concentrations found would not appear to be entirely dependant on the degree of protein binding.

Further evidence that the degree of binding to serum does not appear to influence penetration into extravascular tissues was obtained by studying the penetration of penicillins into granuloma tissue. A cotton pellet was inserted into the subcutaneous tissues in the axillary region of rats and 4-5 days afterwards when the granuloma around the pellet had formed, injections of $100 \mathrm{mg}$. $/ \mathrm{kg}$. of the penicillin were given intramuscularly. The rats were killed at $\frac{1}{2}, 1,2,4$ and 6 hours afterwards. The granuloma was removed, homogenised with M/20 phosphate buffer $\mathrm{pH} 7.2$ and the penicillin assayed in the homogenate. A blood sample was taken at each time period. Figure 2 shows that in general the concentration per gram granuloma is less than the blood concentration but there is a considerable amount of fibrous tissue present into which the penicillin cannot penetrate. However the amounts of phenoxymethylpenicillin, phenethicillin and cloxacillin present were similar in relation to the blood levels but ampicillin which is the least protein bound of the four penicillins penetrates much less readily.

Finally we estimated the concentration of penicillin in lymph. Werwey and Williams (1962) have shown that lymphatic levels during continuous intravenous infusion are in general less than the corresponding serum levels, but their method of administration is not one which is normally employed clinically. We therefore decided to study lymphatic levels following intramuscular administration. Groups of five rats were anaesthetised with pentobarbitone and the thoracic lymph duct cannulated. The penicillins were injected intramuscularly into the left hind limb. Samples of lymph and blood, which was taken from the tail vein, were removed for assay at $\frac{1}{2}, 1,2$ and 4 hours. The levels obtained are given in Figure 3.

With phenoxymethylpenicillin, phenethicillin and cloxacillin the levels in the lymph are somewhat higher than those in blood while the levels of ampicillin in lymph are much greater than the corresponding blood levels. It could be argued that since ampicillin is only slightly protein bound that it diffuses more rapidly from the site of injection than the other penicillins which are more heavily bound. It? is then taken up in the lymph in much greater concentration. Our experiments with inflammatory fluids and granuloma tissue would appear to show however that the combination of penicillin and protein does not influence the passage of the penicillin from one site to another.

The albumin content of the peritoneal fluid is slightly higher than serum while the content of the lymph is much less even though the albumin/globulin ratio is increased. It would seem therefore that the higher total levels in lymph and peritoneal fluid than blood are not a consequence of an increased amount of albumin in the tissues.

These results also suggest that the body is not divided into a number of compartments separated by semi-permeable membranes but rather the division between each compartment allows particular molecules to pass through selectively. In other words it is possible to obtain different concentrations in different tissues irrespective of the albumin content on either side of the dividing membrane. 

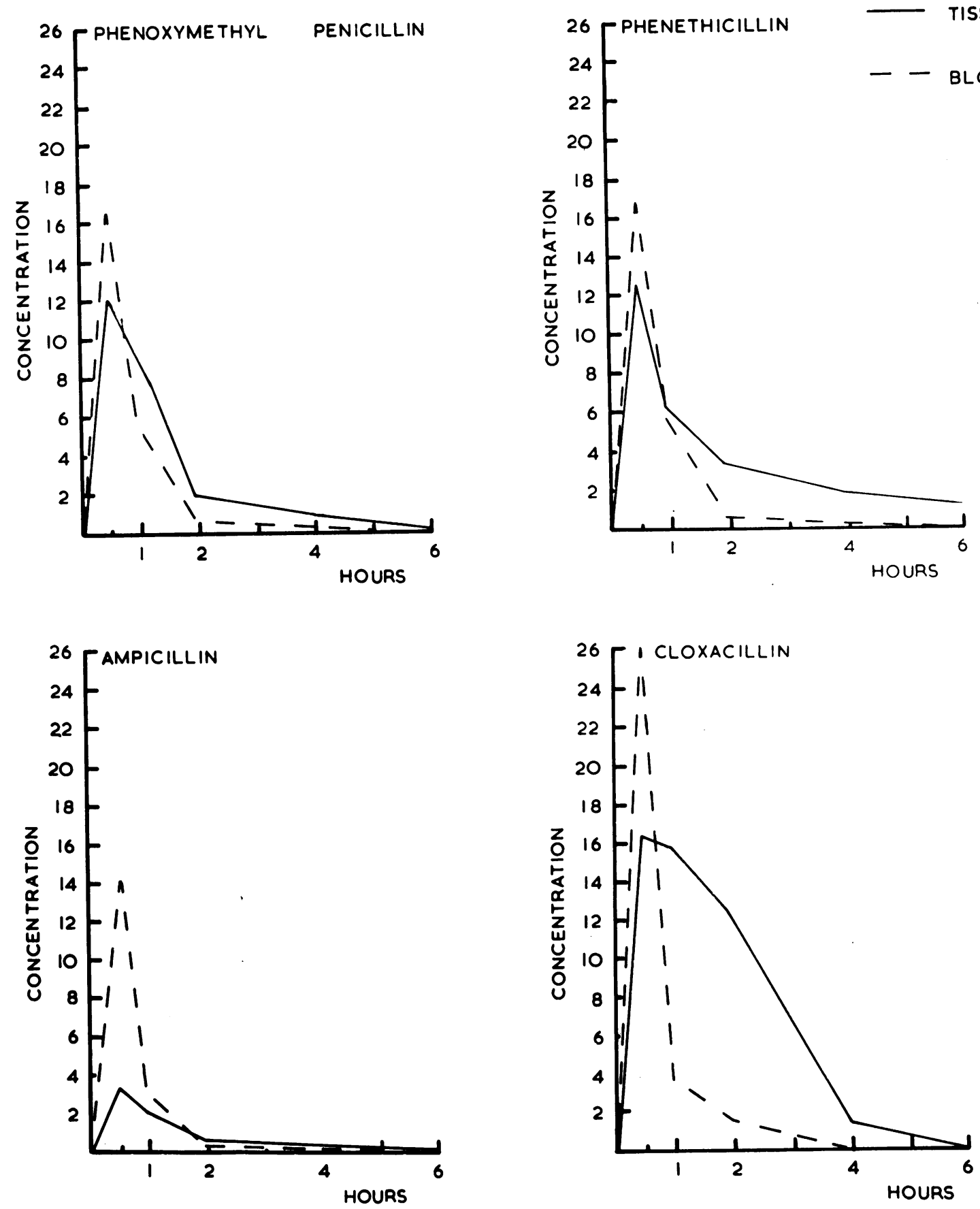

FIG. 2.-Concentrations of Penicillins in Granuloma Tissue $\mu \mathrm{g} . / \mathrm{gm}$. and Blood $\mu \mathrm{g} . / \mathrm{ml}$. following Intramuscular Administration of $100 \mathrm{mg}$. $/ \mathrm{kg}$. of the Penicillins to Rats. 

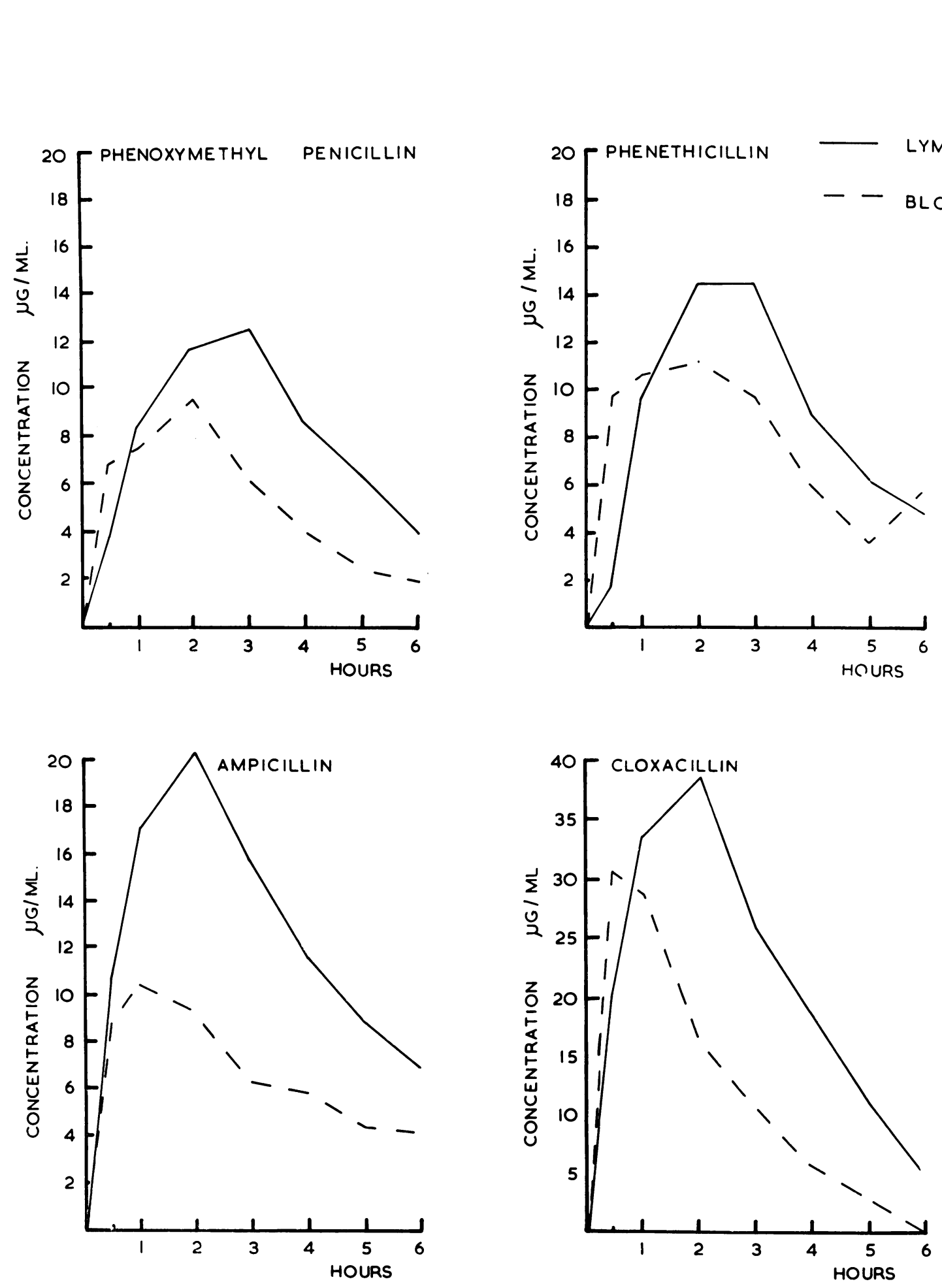

FIG. 3.-Concentrations of Penicillins $\mu \mathrm{g} . / \mathrm{ml}$. in Blood and Lymph following Intramuscular Administration of $100 \mathrm{mg} . / \mathrm{kg}$. of the Penicillins to Rats. 
When comparing the properties of different penicillins with a view to predicting their therapeutic efficacy it is not only necessary to know the concentration of penicillin in the blood and the degree of binding to the serum albumin, it is also necessary to know the levels in the extravascular fluids and the degree of binding to the albumin in these fluids.

REFERENCE

WeRWEY, W. F., and Williams, H. R. (1962), Antimicrobial Agents and Chemotherapy, p. 476. 